\title{
Transmission of Time and Position Variable Cryptology in Fibonacci and Lucas Number Series with Music
}

\author{
Cemil Karaçam $^{1^{*}}$, Firdevs Nur Algül ${ }^{1}$ and Daniel Tavit ${ }^{1}$ \\ ${ }^{1}$ Beşiktaş Bilim ve Sanat Merkezi, Beşiktaş, İstanbul, Turkey \\ * Corresponding author
}

\author{
Article Info \\ Keywords: ASCII Code, Cryptology, $\mathrm{Fi}$ - \\ bonacci Numbers, Lucas Numbers, Mu- \\ sic. \\ 2010 AMS: 00A65, 11B39, 94A60, \\ 97M80. \\ Received: 24 February 2021 \\ Accepted: 28 April 2021 \\ Available online: 30 April 2021
}

\begin{abstract}
Since people existed, they have prioritized confidentiality in information sharing and communication. Although there are independent studies on encryption and music in literature, no study is seen on encryption methods that are created by using the properties of mathematical number strings and can be expressed with musical instruments. The purpose in this research is to develop ideas for an effective encryption method and to create a time and location variable encryption method considering this deficiency in the literature by getting advantage of the additive feature in Fibonacci and Lucas number sequences and moving from here to develop new perspectives on encryption science. In the research letters in alphabet, numbers and 10 of the most used symbols were selected and ASCII codes were determined. The objects to be encrypted are divided into 6 main groups (uppercase vowel, uppercase consonant, lowercase vowel, lowercase consonant letters, numbers, and symbols). ASCII codes are written with the additive property of the Fibonacci and Lucas numbers (Zeckendorf's Theorem) and matched with the corresponding notes. In addition to the first method in the study, the encryption system is encrypted by shifting depending on time. In addition to this method, the encryption system was encrypted by shifting depending on the location. In the last method, the text to be encrypted was encrypted by shifting depending on both location and time. The software of the first stage of the encryption system has been created. The encryption method we have created can be transmitted in both audio and text. Since encryption can be applied with various instruments, it offers variety in terms of data privacy. In the encryption system, people who have a musical ear can audibly decipher the password regardless of the written source. In the research, the same text differs as time and location change. This method allows multiple transformations of a character in a text. With these features, it differs from the encryption methods made until now.
\end{abstract}

\section{Introduction}

People have given importance to confidentiality in their communication since the moment they existed and they have constantly developed new methods in this field. Encoding and encrypting information is a method developed thousands of years ago by empires and states to prevent the information they wanted to be kept secret from falling into the hands of the enemy [1]. These times, when much more primitive encryption methods were used and we have come a long way with the introduction of mechanics and technology into our lives.

Encryption (cryptology), which is one of the sub-branches of mathematics is the science of coding (cryptography), as well as code analysis (cryptanalysis). While code science refers to the creation part of the encryption, code analysis refers to the decryption of the generated code. Its encryption is expressed in the TDK (Turkish Dictionary) as secret texts, encrypted documents science, or analysis. Encryption is the process of making the content of plain text unreadable [1]. Cryptology is mathematics like number theory, that is, it is the application of formulas and algorithms that form the basis of cryptography and encryption analysis [2]. The number of information added to the literature is increasing day by day as a result of increasing discoveries and inventions. Protecting this information is getting more difficult. One of the important methods of protecting information is encryption. The importance of cryptography has increased with the transfer of private, 
commercial, political, and military data of critical privacy in electronic environments [3]. Many different encryption methods have been used from the past to the present. According to the information obtained, the first cryptologist (code scientist) is an Egyptian scribe who lived in BC. 1900s. He created the inscriptions he wrote by encrypted hieroglyphs and used some hieroglyphs that were never used before [1]. One of the first encryption methods that emerged in history was Caesar encryption. In Caesar encryption, instead of every letter seen in the Roman alphabet, the text is encrypted by writing the letter after the corresponding letter in the alphabet. The Enigma machine invented by German scientist Scherbius and Jefferson disks used by the US army can be shown as examples of encryption methods used throughout history.

Music has come to these days by continuously developing since its emergence. Music has a great place and importance in our lives, we are continuously listening to music at home, at school, on trips, and when we go out for walking. The relationship between mathematics and music dates back to the sixth century BC by the ancient Greek philosopher Pythagoras (570-495 BC) [4]. It is known that the mathematical scientist Pythagoras was also very interested in music and found octave and even thin-thick sounds by dividing a wire in the middle. It is seen that they progress in parallel with each other during their development [5]. Other people interested in music and mathematics are $\mathrm{J}$. S. Bach and W. A. Mozart can be shown as examples. It is known that both famous composers have high mathematical intelligence and especially Bach's biggest hobby is mathematics [5]. When the education programs in the middle ages are examined, it is seen that music, mathematics, and astronomy are in the same group.

Art and aesthetics have always been an integral part of mathematics. Many musical instrument producers carry the sound graphics of their instruments to graphics suitable for instruments. Electronic music records are also closely related to graphics. It is essential that mathematicians and musicians collaborate when producing even a piece of music [6].

Studies on music, which can be taught from an early age, emphasize that rhythm studies are associated with mathematics, music experiences are very important in spatial relations and shape comprehension, and that music is based on mathematical thinking and mathematical relations [7]. The Fibonacci number sequence, is the number sequence that first appeared with the "Rabbit Problem", which was discussed in the book "Liber Abaci" published in 1202 by Leonardo of Pisa, known as Fibonacci [8]. The number sequence continues as 1, 1, 2, 3, 5, 8, 13, 21, 34, $55,89,144,233, \ldots$ Each number is the sum of the two numbers preceding it. A similar number sequence is the Lucas number sequence created by French mathematician Edward Lucas. Unlike the Fibonacci number sequence, the Lucas number sequence was continued by starting with the numbers 2 and 1 . Lucas number sequence continues as 2, 1, 3, 4, 7, 11, 18, 29, 47, . [9]. Gül Karadeniz has proved in her research [10] that positive and negative integers can be expressed by Fibonacci numbers and used the Zeckendorf Theorem in her proof.

Theorem 1.1 (The Zeckendorf Theorem[10]). Each $N$ positive integer can be shown as the sum of different positive index Fibonacci numbers. This representation is one way definite. It can be clearly expressed as:

$$
k_{i+1} \leq k_{i}-2 \quad(i=1,2, \ldots, r-1)
$$

$$
k_{i} \geq 2
$$

It is a theorem that states that each positive integer $N$ can be written as

$$
N=F_{k_{1}}+F_{k_{2}}+\cdots+F_{k_{r}}
$$

Proof. The proof is clear if the integer $N$ is itself a Fibonacci number. Assume that the theorem is true for all integers less than or equal to $F_{n}$ and $F_{n+1}>N>F_{n:}$.

$$
N=F_{n}+\left(N-F_{n}\right) ; N-F_{n}<F_{n}
$$

Thus, it is proven that every positive integer can be represented as the sum of positive Fibonacci numbers [10]. It becomes and from our assumption, it is seen that $N-F_{n}$ can be defined as to comply with the terms of Table 1.

There are many studies in the literature on the science of encryption and music. It is possible to collect these studies under the following titles:

- Cryptology techniques and usage areas,

- Concepts used and necessary information in cryptology,

- Encryption systems,

- Relationships between mathematics and encryption,

- The relationship between musical education and mathematical thinking,

- The effect of music on people and their development,

- The relationship between mathematics and music,

- Fibonacci and Lucas numbers.

Çağla Özyılmaz [1] has mentioned the history of cryptology, related basic concepts, and done symmetric encryption applications in her master thesis. In the following parts of the thesis, she talked about Fibonacci numbers and mentioned the codes of various number strings. Zainab Hashim Obard [3], on the other hand, gave information about the basic concepts and gave information about the structure of various algorithms, and made an application and performance analysis on the text and images of different sizes and compared the results in his research. Musa Aghayev [2] talked about basic encryption methods and made determinations about their weaknesses and strengths by performing performance analyzes of encryption methods. Shahin Nasibov [11] made suggestions to increase the security of the RSA encryption system against the Fermat Factorization Method and presented many methods based on this method in his master thesis. Cihan Orhan [6] spoke about the relationship between mathematics and music and their need for each other in his article. He stated that mathematics and music are intertwined and their developments affect each other. Ayperi Dikici [7] investigated the effect of music education on mathematics ability. In his book 'A Geometry of Music: Harmony and Counterpoint' in the Extended Common Practice [12] written by Dmitri Tymoczko, he emphasized the relationship between geometry and music and explained many musical expressions. While Ayten Esi [5] observed the link between mathematics and music in her research, she tried to explain with various examples that one is an integral part 


\begin{tabular}{|l|l|l|l|l|l|l|l|l|l|l|l|l|l|l|l|l|l|l|l|}
\hline & 2 & 3 & 4 & 5 & 6 & 7 & 8 & 9 & 10 & & 2 & 3 & 4 & 5 & 6 & 7 & 8 & 9 & 10 \\
\hline $\mathbf{1}$ & 1 & & & & & & & & & $\mathbf{2 9}$ & & & & & 1 & & 1 & & \\
\hline $\mathbf{2}$ & & 1 & & & & & & & & $\mathbf{3 0}$ & 1 & & & & 1 & & 1 & & \\
\hline $\mathbf{3}$ & & & 1 & & & & & & & $\mathbf{3 1}$ & & 1 & & & 1 & & 1 & & \\
\hline $\mathbf{4}$ & 1 & & 1 & & & & & & & $\mathbf{3 2}$ & & & 1 & & 1 & & 1 & & \\
\hline $\mathbf{5}$ & & & & 1 & & & & & & $\mathbf{3 3}$ & 1 & & 1 & & 1 & & 1 & & \\
\hline $\mathbf{6}$ & 1 & & & 1 & & & & & & $\mathbf{3 4}$ & & & & & & & & 1 & \\
\hline $\mathbf{7}$ & & 1 & & 1 & & & & & & $\mathbf{3 5}$ & 1 & & & & & & & 1 & \\
\hline $\mathbf{8}$ & & & & & 1 & & & & & $\mathbf{3 6}$ & & 1 & & & & & & 1 & \\
\hline $\mathbf{9}$ & 1 & & & & 1 & & & & & $\mathbf{3 7}$ & & & 1 & & & & & 1 & \\
\hline $\mathbf{1 0}$ & & 1 & & & 1 & & & & & $\mathbf{3 8}$ & & & 1 & & & & & 1 & \\
\hline $\mathbf{1 1}$ & & & 1 & & 1 & & & & & $\mathbf{3 9}$ & & & & 1 & & & & 1 & \\
\hline $\mathbf{1 2}$ & 1 & & 1 & & 1 & & & & & $\mathbf{4 0}$ & & & & 1 & & & & 1 & \\
\hline $\mathbf{1 3}$ & & & & & & 1 & & & & $\mathbf{4 1}$ & & & & 1 & & & & 1 & \\
\hline $\mathbf{1 4}$ & 1 & & & & & 1 & & & & $\mathbf{4 2}$ & & & & & 1 & & & 1 & \\
\hline $\mathbf{1 5}$ & & 1 & & & & 1 & & & & $\mathbf{4 3}$ & & & & & 1 & & & 1 & \\
\hline $\mathbf{1 6}$ & & & 1 & & & 1 & & & & $\mathbf{4 4}$ & & & & & 1 & & & 1 & \\
\hline $\mathbf{1 7}$ & 1 & & 1 & & & 1 & & & & $\mathbf{4 5}$ & & & 1 & & 1 & & & 1 & \\
\hline $\mathbf{1 8}$ & & & & 1 & & 1 & & & & $\mathbf{4 6}$ & 1 & & 1 & & 1 & & & 1 & \\
\hline $\mathbf{1 9}$ & 1 & & & 1 & & 1 & & & & $\mathbf{4 7}$ & & & & & & 1 & & 1 & \\
\hline $\mathbf{2 0}$ & & 1 & & 1 & & 1 & & & & $\mathbf{4 8}$ & 1 & & & & & 1 & & 1 & \\
\hline $\mathbf{2 1}$ & & & & & & & 1 & & & $\mathbf{4 9}$ & & 1 & & & & 1 & & 1 & \\
\hline $\mathbf{2 2}$ & 1 & & & & & & 1 & & & $\mathbf{5 0}$ & & & 1 & & & 1 & & 1 & \\
\hline $\mathbf{2 3}$ & & 1 & & & & & 1 & & & $\mathbf{5 1}$ & 1 & & 1 & & & 1 & & 1 & \\
\hline $\mathbf{2 4}$ & & & 1 & & & & 1 & & & $\mathbf{5 2}$ & & & & 1 & & 1 & & 1 & \\
\hline $\mathbf{2 5}$ & 1 & & 1 & & & & 1 & & & $\mathbf{5 3}$ & 1 & & & 1 & & 1 & & 1 & \\
\hline $\mathbf{2 6}$ & & & & 1 & & & 1 & & & $\mathbf{5 4}$ & & 1 & & 1 & & 1 & & 1 & \\
\hline $\mathbf{2 7}$ & 1 & & & 1 & & & 1 & & & $\mathbf{5 5}$ & & & & & & & & & 1 \\
\hline $\mathbf{2 8}$ & & 1 & & 1 & & & 1 & & & & & & & & & & & & \\
\hline
\end{tabular}

Table 1: Zeckendorf Representation of Positive Integers with Fibonacci Numbers

of the other and emphasized that mathematics is intertwined with music. As a result, she emphasizes the interweaving of science and art, as it was noticed in Ancient Greece, by taking the relationship of mathematics and music as an example. Uzay Bora [13] in his article on "A Basic Point Where Science and Art Cross: The Relationship Between Mathematics and Music", examines the relationship between musical elements and mathematics. The article includes mathematical explanations of various concepts such as pitch, timbre, intervals, Pythagorean coma, equal regular system, and examples suitable for thematic transformations and harmonic distance calculations. Eric Riedel's [14] research is a study conducted to compare musical education and mathematics on 6th-grade students of a school in Atlanta. As a result of the study, it was determined that students who received music education had higher mathematics application grades than students who did not. Gülay Göğüş [15] investigated the effect of music education on mathematics lesson scores in her study and states that music education has a positive effect on mathematics lessons. Kaya [16] mentioned the importance of scientific methods in his/her study and investigated the interactions of arithmetic and music in ancient times. Selen Beytekin [17] explained the fundamentals of music and fracture geometry and explained the interactions of jazz music and geometry to explain jazz and its theoretical foundations. Ufuk Biçak [18] focused on explaining the harmony theory based on the relationship between music and mathematics in his/her master's thesis. Firstly, he/she examined Pythagoras' works in the field of music, and then explained the New Harmony theory and the applications of the theory. İlhami Kaya [19] conducted various studies on the instrument named monochord designed by Pythagoras, and also included the following expressions for the relationship between music and mathematics in the past: "Before history, musical sounds were expressed in numbers and proportions rather than notes.". Gareth Roberts [20] mentioned the relationship between music and mathematics disciplines in his published book. Book; covers topics such as simple proportions and the Pythagorean theory of musical scales and harmonic consonant and harmony series, musical symmetries, and group theory. Sümeyye Bakım [4] first mentioned mathematics as the basis of music. She explained mathematical expressions corresponding to some musical concepts, examined the relationship between mathematics and music. The studies conducted on the use of the Fibonacci Sequence and the Golden Ratio in instrument making and whether some polyphonic music composers take this ratio into account during the process of composing their works have been examined and their accuracy has been discussed. Cennet Bolat [9] used the Binet formula and matrix algebra, which generalized some properties of k-Fibonacci and k-Lucas numbers and are a generalization of Fibonacci and Lucas numbers. Gökhan Kuzuoğlu [8] stated the characteristics of Fibonacci and Lucas number sequences in his thesis. In the 'Fabulous Fibonacci Numbers' written by Alfred S. Posamentier and Ingmar Lehmann [21], the history of the Fibonacci number sequence, where it is used, its interactions with various disciplines, and the properties of the Fibonacci-Lucas number sequences are mentioned in detail. Gül Karadeniz [10] prepared a thesis on Fibonacci and Pell numbers and Zeckendorf proof. In her thesis, she determined that all numbers (positive and negative indexes) can be expressed with Fibonacci numbers and created an algorithm on this subject.

Although there are studies in the literature that have dealt with the science of encryption from various aspects with various methods, there is no study on the time-variant encryption method using the additive property in Fibonacci and Lucas number sequences. 


\subsection{Purpose of the research}

Although there are independent researches on the science of encryption, there is no study in the literature on encryption methods that are created using the properties of mathematical number strings that can be expressed with musical instruments. The purpose of this research is to create a time and location variable encryption method by taking advantage of the additive feature of the Fibonacci and Lucas number sequences, considering this deficiency in the literature, and to develop ideas for an effective encryption method by creating new perspectives on the science of encryption.

Hypothesis: Fibonacci and Lucas number-based and mathematics related to music

1. Encryption algorithm,

2. Time data based on the encryption algorithm,

3. Encryption algorithm based on location information,

4. Can a double-layer encryption algorithm be created based on time and location information?

\section{Method}

In the research mainly, literature review, content analysis, and field scanning method were used. In the first stage of the research, 10 of the most used letters, numbers, and symbols in the alphabet were selected and ASCII codes were determined. ASCII codes are written with the additive property of the Fibonacci numbers in the largest and shortest form that can be written and matched with the corresponding notes. In overlapping encodings, the last Fibonacci number is split once again.

\begin{tabular}{|c|c|c|c|c|c|c|c|}
\hline 1 & 2 & 3 & 4 & 5 & 6 & 7 & 8 \\
\hline $\mathrm{C}$ & $\mathrm{D}$ & $\mathrm{E}$ & $\mathrm{F}$ & $\mathrm{G}$ & $\mathrm{A}$ & $\mathrm{B}$ & $\mathrm{C}$ \\
\hline
\end{tabular}

Table 2: Note Matches (C major tone sequence example)

\begin{tabular}{|c|c|c|c|c|c|c|c|}
\hline 1 & 2 & 3 & 4 & 5 & 6 & 7 & 8 \\
\hline G & A & B & C & D & E & F & G \\
\hline
\end{tabular}

Table 3: Note Matches (G major tone sequence example)

\begin{tabular}{|c|c|c|c|c|c|c|c|}
\hline 1 & 2 & 3 & 4 & 5 & 6 & 7 & 8 \\
\hline D & E & F & G & A & B & C & D \\
\hline
\end{tabular}

Table 4: Note Matches (D major tone sequence example)

\begin{tabular}{|c|c|c|c|c|c|c|c|}
\hline 1 & 2 & 3 & 4 & 5 & 6 & 7 & 8 \\
\hline B & C & D & E & F & G & A & B \\
\hline
\end{tabular}

Table 5: Note Matches (B major tone sequence example)

The numbers in the expansions written with Fibonacci numbers are matched to the relevant note of the number remaining from the division of $7(\bmod 7)$ as in Table 2.

\begin{tabular}{|c|c|c|}
\hline Groups & Number Sequences Used & Music Tone Used \\
\hline Uppercase Vowels & Fibonacci Number Sequence & C Major \\
\hline Uppercase Consonants & Fibonacci Number Sequence & C Major \\
\hline Lowercase Vowels & Fibonacci Number Sequence & G Major \\
\hline Lowercase Consonants & Fibonacci Number Sequence & G Major \\
\hline Numbers & Lucas Number Sequence & D Major \\
\hline Symbols & Fibonacci and Lucas Number Sequences & B Major \\
\hline
\end{tabular}

Table 6: Number Sequences and Tones Used

We created our method by giving ASCII code for letters in the Turkish alphabet but not existing in the English alphabet. We matched the

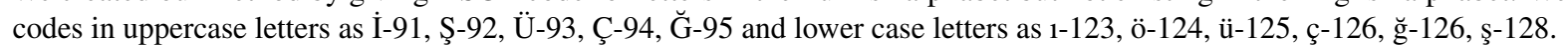

\subsection{Encryption of letters}

We divided the letters in our alphabet into 4 parts. These are: 


\begin{tabular}{|c|c|c|c|}
\hline Code & Letter & Code & Letter \\
\hline 065 & $\mathrm{~A}$ & 066 & $\mathrm{~B}$ \\
\hline 067 & $\mathrm{C}$ & 068 & $\mathrm{D}$ \\
\hline 069 & $\mathrm{E}$ & 070 & $\mathrm{~F}$ \\
\hline 071 & $\mathrm{G}$ & 072 & $\mathrm{H}$ \\
\hline 073 & $\mathrm{I}$ & 074 & $\mathrm{~J}$ \\
\hline 075 & $\mathrm{~K}$ & 076 & $\mathrm{~L}$ \\
\hline 078 & $\mathrm{~N}$ & 077 & $\mathrm{M}$ \\
\hline 080 & $\mathrm{P}$ & 079 & $\mathrm{O}$ \\
\hline 082 & $\mathrm{R}$ & 081 & $\mathrm{Q}$ \\
\hline 084 & $\mathrm{~T}$ & 083 & $\mathrm{~S}$ \\
\hline 086 & $\mathrm{~V}$ & 085 & $\mathrm{U}$ \\
\hline 088 & $\mathrm{X}$ & 087 & $\mathrm{~W}$ \\
\hline 090 & $\mathrm{Z}$ & 089 & $\mathrm{Y}$ \\
\hline
\end{tabular}

Table 7: ASCII Codes - Uppercase Letter (Gökhan, 2013)

\begin{tabular}{|c|c|c|c|}
\hline Code & Letter & Code & Letter \\
\hline 097 & $\mathrm{~A}$ & 098 & $\mathrm{~b}$ \\
\hline 099 & $\mathrm{C}$ & 100 & $\mathrm{~d}$ \\
\hline 101 & $\mathrm{E}$ & 102 & $\mathrm{f}$ \\
\hline 103 & $\mathrm{G}$ & 104 & $\mathrm{~h}$ \\
\hline 105 & $\mathrm{I}$ & 106 & $\mathrm{~J}$ \\
\hline 107 & $\mathrm{~K}$ & 108 & $\mathrm{l}$ \\
\hline 109 & $\mathrm{M}$ & 110 & $\mathrm{n}$ \\
\hline 111 & $\mathrm{O}$ & 112 & $\mathrm{p}$ \\
\hline 113 & $\mathrm{Q}$ & 114 & $\mathrm{r}$ \\
\hline 115 & $\mathrm{~S}$ & 116 & $\mathrm{t}$ \\
\hline 117 & $\mathrm{U}$ & 118 & $\mathrm{v}$ \\
\hline 119 & $\mathrm{~W}$ & 120 & $\mathrm{x}$ \\
\hline 121 & $\mathrm{Y}$ & 122 & $\mathrm{z}$ \\
\hline
\end{tabular}

Table 8: ASCII Codes - Lowercase Letter [22]

\begin{tabular}{|c|c|c|}
\hline $\mathbf{A}$ & $55+8+2$ & $\mathrm{~A} \mathrm{C} \mathrm{D}$ \\
\hline $\mathbf{E}$ & $55+13+1$ & $\mathrm{~A} \mathrm{~A} \mathrm{C}$ \\
\hline $\mathbf{I}$ & $55+13+5$ & $\mathrm{~A} \mathrm{~A} \mathrm{G}$ \\
\hline$\dot{\mathbf{I}}$ & $(55+34+2) 55+21+13+2$ & $\mathrm{~A} \mathrm{~B} \mathrm{~A} \mathrm{D}$ \\
\hline $\mathbf{O}$ & $55+21+3$ & $\mathrm{~A} \mathrm{~B} \mathrm{E}$ \\
\hline$\ddot{\mathbf{O}}$ & $55+34+3$ & $\mathrm{~A} \mathrm{~A} \mathrm{E}$ \\
\hline $\mathbf{U}$ & $55+21+8+1$ & $\mathrm{~A} \mathrm{~B} \mathrm{C} \mathrm{C}$ \\
\hline$\ddot{\mathbf{U}}$ & $55+34+3+1$ & $\mathrm{~A} \mathrm{~A} \mathrm{E} \mathrm{C}$ \\
\hline
\end{tabular}

Table 9: Encryption of Uppercase Vowels

\subsubsection{Uppercase letters}

As seen in Table 9, the eight uppercase vowel letters in our alphabet are encoded with Fibonacci numbers and matched with notes given to the numbers in the sequence. Only the number 34 was opened as $21+13$ as a result of the overlapping in the letter I.

For example, let's encrypt the letter E. The ASCII code of the letter E is 69. It opens in Fibonacci numbers with a total of 69 and the number is expressed as $55+13+1$. These numbers are converted into notes by matching the remaining digits after dividing from the 7 th parts $(\bmod 7)$ with the strings of notes.

$$
55 \equiv 6 \quad(\bmod 7) \quad 13 \equiv 6 \quad(\bmod 7) \quad 1 \equiv 1 \quad(\bmod 7)
$$

Since the sequence of $\mathrm{C}$ major is used in the encoding of the uppercase vowels, the rest are matched with the appropriate notes as in Table 2.

$$
6 \equiv A \quad 6 \equiv A \quad 1 \equiv C
$$

\subsubsection{Uppercase consonants}

As seen in Table 13, 22 uppercase consonants are encrypted. Only because of the inner conflicts in the letters T, Y and Z, 8 for the letter T is defined and the number 34 in the letters $\mathrm{Y}$ and $\mathrm{Z}$ were once again opened.

Let's encrypt the letter $\mathrm{S}$ for example. ASCII code of the letter $\mathrm{S}$ is 83 . The number 83 is expressed in its shortest form with Fibonacci numbers. The expansion is $55+21+5+2$. These numbers are converted into notes by matching with the remaining numbers from the division of 7 th parts $(\bmod 7)$ and so matched with the strings of notes. 


\begin{tabular}{|c|c|c|}
\hline B & $55+8+3$ & A C E \\
\hline $\mathbf{C}$ & $55+8+3+1$ & A C E C \\
\hline $\mathbf{C}$ & $55+34+5$ & A A G \\
\hline $\mathbf{D}$ & $55+13$ & A A \\
\hline $\mathbf{F}$ & $55+13+2$ & A A D \\
\hline $\mathbf{G}$ & $55+13+3$ & A A E \\
\hline $\mathbf{G}$ & $55+34+5+1$ & A A G C \\
\hline $\mathbf{H}$ & $55+13+3+1$ & A A E C \\
\hline $\mathbf{J}$ & $55+13+5+1$ & A A G C \\
\hline $\mathbf{K}$ & $55+13+5+2$ & A A G D \\
\hline $\mathbf{L}$ & $55+21$ & A B \\
\hline $\mathbf{M}$ & $55+21+1$ & A B C \\
\hline $\mathbf{N}$ & $55+21+2$ & A B D \\
\hline $\mathbf{P}$ & $55+21+3+1$ & A B E C \\
\hline $\mathbf{Q}$ & $55+21+5$ & A B G \\
\hline $\mathbf{R}$ & $55+21+5+1$ & A B G C \\
\hline $\mathbf{S}$ & $55+21+5+2$ & A B G D \\
\hline $\mathbf{S}$ & $55+34+5+2$ & A G D \\
\hline $\mathbf{T}$ & $(55+21+8) 55+21+5+3$ & A B G E \\
\hline $\mathbf{V}$ & $55+21+8+2$ & A B C D \\
\hline $\mathbf{W}$ & $55+21+8+3$ & A B C E \\
\hline $\mathbf{X}$ & $55+21+8+3+1$ & A B C E C \\
\hline $\mathbf{Y}$ & $(55+34) 55+21+13$ & A B A \\
\hline $\mathbf{Z}$ & $(55+34+1) 55+21+13+1$ & A B A C \\
\hline & &
\end{tabular}

Table 10: Encryption of Uppercase Consonants

$$
55 \equiv 6 \quad(\bmod 7) \quad 21 \equiv 0 \quad(\bmod 7) \quad 5 \equiv 5 \quad(\bmod 7) \quad 2 \equiv 2 \quad(\bmod 7)
$$

Since the sequence of $\mathrm{C}$ major is used in the encoding of the uppercase vowels, the rest are matched with the appropriate notes as in Table 2.

$$
6 \equiv A \quad 0 \equiv B \quad 5 \equiv G \quad 2 \equiv D
$$

\subsubsection{Lowercase vowels}

\begin{tabular}{|c|c|c|}
\hline $\mathbf{a}$ & $89+8$ & D G \\
\hline $\mathbf{e}$ & $89+8+3+1$ & D G B G \\
\hline $\mathbf{1}$ & $(89+34) 89+21+13$ & D F E \\
\hline $\mathbf{i}$ & $89+13+3$ & D E B \\
\hline $\mathbf{o}$ & $89+21+1$ & D F G \\
\hline$\ddot{\mathbf{o}}$ & $(89+34+1) 89+21+13+1$ & D F E G \\
\hline $\mathbf{u}$ & $89+21+5+2$ & D F D A \\
\hline$\ddot{\mathbf{u}}$ & $(89+34+2) 89+21+13+2$ & D F E A \\
\hline
\end{tabular}

Table 11: Encryption of Lowercase Vowels

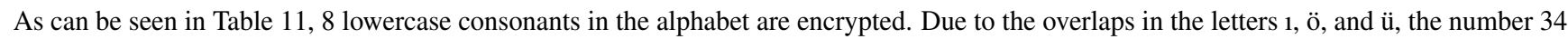
has been opened as $21+13$.

For example, let's encrypt the letter i. The ASCII code of letter i is 105 . The number 105 is expressed in shortest form with Fibonacci numbers. The expansion will be as $89+13+3$. These numbers are converted into notes by matching the remaining numbers from the 7 th parts $(\bmod 7)$ with the strings of notes.

$$
89 \equiv 5 \quad(\bmod 7) \quad 13 \equiv 6 \quad(\bmod 7) \quad 3 \equiv 3 \quad(\bmod 7)
$$

Since $\mathrm{G}$ major is used in the encoding of small vowels, the rest are matched with the appropriate notes as in Table 3.

$$
5 \equiv D \quad 6 \equiv E \quad 3 \equiv B
$$

\subsubsection{Lowercase consonants}

As seen in Table 15, 22 small consonants are encrypted. The numbers 34 and 8 are opened once again due to the overlap in the letters $\breve{g}$ and y. For example, let's encrypt the letter $\mathrm{k}$. The ASCII code of the letter $\mathrm{k}$ is 107 . The number 107 is expressed as shortest in Fibonacci numbers. Expansion will be $89+13+5$ and every number is matched with the notes. These numbers are converted into notes by matching the remaining numbers from the 7 th parts $(\bmod 7)$ with the strings of notes. 


\begin{tabular}{|c|c|c|}
\hline b & $89+8+1$ & D G G \\
\hline c & $89+8+2$ & D G A \\
\hline ç & $89+34+3$ & D E B \\
\hline d & $89+8+3$ & D G B \\
\hline f & $89+13$ & D E \\
\hline g & $89+13+1$ & D E G \\
\hline g & $(89+34+3+1) 89+21+13+3+1$ & D F E B G \\
\hline h & $89+13+2$ & D E A \\
\hline j & $89+13+3+1$ & D E B G \\
\hline k & $89+13+5$ & D E D \\
\hline l & $89+13+5+1$ & D E D G \\
\hline m & $89+13+5+2$ & D E D A \\
\hline n & $89+21$ & D FA \\
\hline p & $89+21+2$ & D F A \\
\hline q & $89+21+3$ & D F B \\
\hline r & $89+21+3+1$ & D F B G \\
\hline s & $89+21+5$ & D F D \\
\hline ş & $89+34+5$ & D E D \\
\hline t & $89+21+5+1$ & D F D G \\
\hline v & $(89+21+8) 89+21+5+3$ & D F D B \\
\hline w & $89+21+8+1$ & D F G G \\
\hline x & $89+21+8+2$ & D F G A \\
\hline y & $89+21+8+3$ & D F G B \\
\hline z & $89+21+8+3+1$ & D F G B G \\
\hline & &
\end{tabular}

Table 12: Encryption of Lowercase Consonants

$$
89 \equiv 5 \quad(\bmod 7) \quad 13 \equiv 6 \quad(\bmod 7) \quad 5 \equiv 5 \quad(\bmod 7)
$$

Since $\mathrm{G}$ major is used in the encoding of small consonants, the rest are matched with the appropriate notes as in Table 3.

$$
5 \equiv D \quad 6 \equiv E
$$

\subsection{Encryption of symbols and numbers}

\begin{tabular}{|c|c|c|c|c|c|c|c|c|c|c|}
\hline & Simge1 & S2 & S3 & S4 & S5 & S6 & S7 & S8 & S9 & S10 \\
\hline Fibonacci & 1 & 1 & 2 & 3 & 5 & 8 & 13 & 21 & 34 & 55 \\
\hline Lucas & 2 & 1 & 3 & 4 & 7 & 11 & 18 & 29 & 47 & 76 \\
\hline
\end{tabular}

Table 13: Encryption of Lowercase Consonants

As seen in Table 13, each symbol is expressed as the sum of the relevant Fibonacci and Lucas numbers, respectively.

\begin{tabular}{|c|c|c|}
\hline (simge 1). & $1+2$ & B C \\
\hline (simge 2), & $1+1$ & B B \\
\hline (simge 3) ? & $2+3$ & C D \\
\hline (simge 4) ! & $3+4$ & D E \\
\hline (simge 5) - & $5+7$ & F A \\
\hline (simge 6) + & $8+11$ & B E \\
\hline (simge 7) : & $13+8$ & G B \\
\hline (simge 8) “’ & $21+29$ & A B A B \\
\hline (simge 9) ( ) & $34+47$ & G F \\
\hline (simge 10) @ & $55+76$ & G G \\
\hline
\end{tabular}

Table 14: Encryption of Symbols

In Table 14, the 10 most used symbols and their corresponding notes are determined. The symbol " " is inverted because it coincides with the number 6. Fibonacci and Lucas numbers are used in the encryption of symbols.

The " " (quotation mark) symbol matches the same notes as the letter L, so encrypted as repeating the same notes.

For example, let's encrypt the () symbol. The Fibonacci and Lucas numbers to which this symbol (S9) is paired are 34 and 47 , respectively. These numbers are divided into 7 with the method mentioned before and the rest are encrypted by matching the notes.

The difficulty is faced in using the Fibonacci sequence of numbers when encrypting numbers. Therefore, the Lucas number sequence is used when encrypting the numbers. 10 digits are encrypted as seen in Table 14. The Lucas numbers to which the numbers are matched are 


\begin{tabular}{|c|c|c|}
\hline $\mathbf{0}$ & $1+1$ & D D \\
\hline $\mathbf{1}$ & 1 & D \\
\hline $\mathbf{2}$ & $2+1$ & E D \\
\hline $\mathbf{3}$ & $3+1$ & F D \\
\hline $\mathbf{4}$ & $5+2$ & A E \\
\hline $\mathbf{5}$ & $8+3$ & D F \\
\hline $\mathbf{6}$ & $13+5$ & B A \\
\hline $\mathbf{7}$ & $21+8$ & C D \\
\hline $\mathbf{8}$ & $34+13$ & B B B B \\
\hline $\mathbf{9}$ & $55+21$ & B C \\
\hline
\end{tabular}

Table 15: Encryption of Numbers

expressed in the shortest form using the additive expressibility feature of the Fibonacci numbers, these additive expressions are converted to notes over mode 7 .

Since the number 8 and the symbol,(comma) correspond to the same notes as 8 , B notes are repeated.

For example, let's encrypt the number 9. This number matches Lucas number 10, which is 76 . The additive expression of this number with Fibonacci numbers is $55+21$. This additive expression is converted into notes over mode 7 and encrypted.

\subsection{Music terms used and transitions in encoding}

- Stacatto: Intermittent playing or singing

- Silencio: Waiting without playing or singing

- Vibrato: Musical effect consisting of regular change of pitch

- Tone: It is a concept that is based on a series of majors and minors.

When we start the sentence, we added a different feature to each section to understand which group the original note that the sequence belongs to.

- By doing staccato in numbers.

- Making vibrato on the violin in symbols,

- Playing normally in letters

We also used different wait times when switching between the two groups (e.g. symbols and numbers) to indicate which groups were switched between.

Between the same groups $\rightarrow$ 1-beat of silence,

Letter - Number $\rightarrow 2$ beats of silence,

Number - Symbol $\rightarrow 3$ beats of silence,

Letter - Symbol $\rightarrow 4$ beats of silence are used.

\subsection{Time, location, and time-location variable encryption}

The time structure that we will use in encryption is divided into 6 main sections in accordance with our main structure as can be seen in Table 18.

\begin{tabular}{|l|l|l|l|l|l|}
\hline Day & Month & Year & Hour & Minute & Second \\
\hline
\end{tabular}

Table 16: Time Structure Used

1. 6 different elements of our alphabet are matched with the components of time.

2. Components of time are determined.

3. The numerical equivalents of the units of time are divided by the mode value and the remainder are determined.

4. Units are shifted according to the remaining values.

5. For encryption, the remainder is negatively shifted.

The location structure that we will use in encryption is firstly divided into 2 parts as parallel and meridian, as seen in Table 8 . After that, both are divided into their 3 components.

\begin{tabular}{|c|l|l|l|l|l|}
\hline \multicolumn{3}{|c|}{ Parallel } & \multicolumn{3}{c|}{ Meridian } \\
\hline Degree & Minute & Second & Degree & Minute & Second \\
\hline
\end{tabular}

Table 17: Used Location Structure 


\subsection{Application}

1. For our research to be more understandable, let's explain the simplest application with an example.

Example 2.1. Let's turn the TüBitAK2020 word to notes.

$$
\begin{aligned}
& T=A B G E \text { (Table 10) } \\
& \ddot{u}=D F E \text { A (Table 11) } \\
& B=A C E \text { (Table 10) } \\
& i=A B A D \text { (Table 11) } \\
& t=D F D G \text { (Table 12) } \\
& A=A C D E \text { (Table 9) } \\
& K=A A G D \text { (Table 10) } \\
& 2=E D \text { (Table 15) } \\
& 0=D D(\text { Table } 15) \\
& 2=E D \text { (Table 15) } \\
& 0=D D(\text { Table 15) } \\
& \text {. = B C (Table 14) }
\end{aligned}
$$

2. Time-Based Application

(a) Time information is received.

(b) The number written with 6-digit $(1,2,3,4,5,6)$ elements is taken.

(c) The received number is matched with groups and time information.

Let's match the 6 main elements of time with the 6 main structures that will create our text.

\begin{tabular}{|l|l|}
\hline \multicolumn{2}{|c|}{ 1st Group } \\
\hline 1 & UPP.VOWEL \\
\hline 2 & UPP.CONSONANT \\
\hline 3 & LOW.VOWEL \\
\hline 4 & LOW.CONSONANT \\
\hline 5 & NUMBER \\
\hline 6 & SYMBOL \\
\hline
\end{tabular}

\begin{tabular}{|l|l|}
\hline \multicolumn{2}{|c|}{ 2nd Group } \\
\hline 1 & DAY \\
\hline 2 & MONTH \\
\hline 3 & YEAR \\
\hline 4 & HOUR \\
\hline 5 & MINUTE \\
\hline 6 & SECOND \\
\hline
\end{tabular}

Example 2.2. Let's take the number 356124. Let our time be 09.01.2020 / 17.48.53.

In this case:

$\begin{array}{lll}\text { Uppercase vowels } & \leftrightarrow & \text { Year } \\ \text { Uppercase consonants } & \leftrightarrow & \text { Minute } \\ \text { Lowercase vowels } & \leftrightarrow & \text { Second } \\ \text { Lowercase consonants } & \leftrightarrow & \text { Day } \\ \text { Number } & \leftrightarrow & \text { Month } \\ \text { Symbol } & \leftrightarrow & \text { Hour }\end{array}$

As a result of this match, transactions are done and the remainder is calculated one by one, each group is shifted as much as the remainder, our text is then encrypted.

$$
\begin{array}{lll}
\text { Day } & \leftrightarrow & (\bmod 24) \\
\text { Month } & \leftrightarrow & (\bmod 10) \\
\text { Year } & \leftrightarrow & (\bmod 8) \\
\text { Hour } & \leftrightarrow & (\bmod 10) \\
\text { Minute } & \leftrightarrow & (\bmod 24) \\
\text { Second } & \leftrightarrow & (\bmod 8)
\end{array}
$$

\begin{tabular}{|l|c|c|c|c|c|c|}
\hline & $\begin{array}{c}\text { Uppercase } \\
\text { Vowel }\end{array}$ & $\begin{array}{c}\text { Uppercase } \\
\text { Consonant }\end{array}$ & $\begin{array}{c}\text { Lowercase } \\
\text { Vowel }\end{array}$ & $\begin{array}{c}\text { Lowercase } \\
\text { Consonant }\end{array}$ & Number & Symbol \\
\hline MODE & 8 & 24 & 8 & 24 & 10 & 10 \\
\hline MATCH & 3 & 5 & 6 & 1 & 2 & 4 \\
\hline TIME & 2020 & 48 & 53 & 09 & 01 & 17 \\
\hline REMAINDER/SHIFT & 4 & 0 & 5 & 9 & 1 & 7 \\
\hline
\end{tabular}

Table 18: Time Based Application (Shift Determination)

The shift is calculated by dividing the time values according to the relevant mode and taking the remainder.

$$
\begin{array}{lll}
\text { Uppercase vowels } & : & 2020 \equiv 4(\bmod 8) \\
\text { Uppercase consonants } & : 48 \equiv 0(\bmod 24) \\
\text { Lowercase vowels } & : & 53 \equiv 5(\bmod 8) \\
\text { Lowercase consonants } & : & 09 \equiv 9(\bmod 24) \\
\text { Number } & : 01 \equiv 1(\bmod 10) \\
\text { Symbol } & : 17 \equiv 7(\bmod 10)
\end{array}
$$


Example 2.3. For example: The letter ï is 24 as seen in Table 8. When it matches, its value is 09. When the number 09 is divided into mod24, the remainder is 9 . Therefore, the letter $\ddot{u}$ is shifted by 9 letters and becomes the letter 0.

$$
\begin{aligned}
& T \rightarrow T \rightarrow A B G E \text { (Table 10) } \\
& \ddot{u} \rightarrow o \rightarrow D F G(\text { Table 11) } \\
& B \rightarrow B \rightarrow \text { ACE (Table 10) } \\
& i \rightarrow a \rightarrow D G(\text { Table 11) } \\
& t \rightarrow t \rightarrow D G B \text { (Table 12) } \\
& A \rightarrow O \rightarrow A B E \text { (Table 9) } \\
& K \rightarrow K \rightarrow \text { AAGD (Table 10) } \\
& 2 \rightarrow 3 \rightarrow F D \text { (Table 15) } \\
& 0 \rightarrow 1 \rightarrow D \text { (Table 15) } \\
& 2 \rightarrow 3 \rightarrow F D \text { (Table 15) } \\
& 0 \rightarrow 1 \rightarrow D \text { (Table 15) } \\
& \rightarrow \text { “” } \rightarrow \text { A B AB (Table 14) }
\end{aligned}
$$

Encryption can be done by repeating the same transactions in reverse.

\begin{tabular}{|c|c|c|}
\hline Degree & $\leftrightarrow$ & $(\bmod 10)$ \\
\hline Minute & $\leftrightarrow$ & $(\bmod 24)$ \\
\hline Second & $\leftrightarrow$ & $(\bmod 10)$ \\
\hline Degree & $\leftrightarrow$ & $(\bmod 8)$ \\
\hline Minute & $\leftrightarrow$ & $(\bmod 24)$ \\
\hline Seconds & $\leftrightarrow$ & $(\bmod 8)$ \\
\hline
\end{tabular}

3. Location-Based Application

(a) Location information is received.

(b) The number written with 6-digit $(1,2,3,4,5,6)$ elements is taken.

(c) The received number is matched with groups and location information.

Let's match the 6 main elements of the position with the 6 main structures that will form our text.

\begin{tabular}{|c|l|}
\hline \multicolumn{2}{|c|}{ 1st Group } \\
\hline 1 & UPP.VOWEL \\
\hline 2 & UPP.CONSONANT \\
\hline 3 & LOW.VOWEL \\
\hline 4 & LOW.CONSONANT \\
\hline 5 & NUMBER \\
\hline 6 & SYMBOL \\
\hline
\end{tabular}

\begin{tabular}{|c|c|}
\hline \multicolumn{2}{|c|}{2 nd Group } \\
\hline 1 & Degree \\
\hline 2 & Minute \\
\hline 3 & Second \\
\hline 4 & Degree \\
\hline 5 & Minute \\
\hline 6 & Second \\
\hline
\end{tabular}

Example 2.4. Let's take the number 654231 and let's choose the location as $49^{\circ} 3^{\prime} 49^{\prime \prime}$ North $29^{\circ} 0^{\prime} 36^{\prime \prime}$ East.

$\begin{array}{lll}\text { Uppercase vowels } & \leftrightarrow & \text { Second (East) } \\ \text { Uppercase consonants } & \leftrightarrow & \text { Minute (East) } \\ \text { Lowercase vowels } & \leftrightarrow & \text { Degree (East) } \\ \text { Lowercase consonants } & \leftrightarrow & \text { Minute (North) } \\ \text { Number } & \leftrightarrow & \text { Second (North) } \\ \text { Symbol } & \leftrightarrow & \text { Degree (North) }\end{array}$

As a result of this match, transactions are done and the remainder is calculated one by one, each group is shifted as much as the remainder, our text is then encrypted.

\begin{tabular}{|l|c|c|c|c|c|}
\hline & $\begin{array}{c}\text { Uppercase } \\
\text { Vowel }\end{array}$ & $\begin{array}{c}\text { Uppercase } \\
\text { Consonant }\end{array}$ & $\begin{array}{c}\text { Lowercase } \\
\text { Vowel }\end{array}$ & $\begin{array}{c}\text { Lowercase } \\
\text { Consonant }\end{array}$ & Number \\
\hline MODE & 8 & 24 & 8 & 24 & 10 \\
\hline MATCH & 6 & 5 & 4 & 2 & 3 \\
\hline TIME & 36 & 0 & 29 & 3 & 49 \\
\hline REMAINDER/SHIFT & 4 & 0 & 5 & 0 & 9 \\
\hline
\end{tabular}




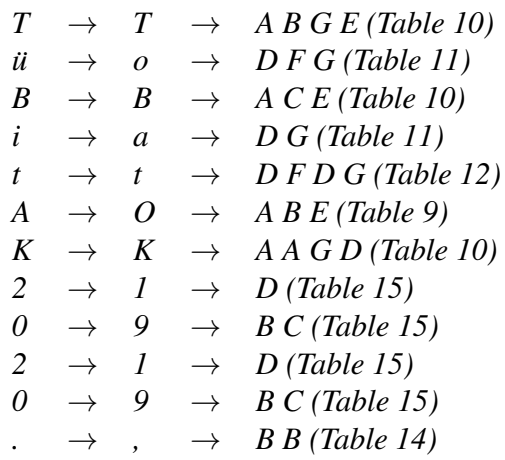

4. Location and Time-Based Application In the location and time-based application, encryption is performed firstly by location. This application will continue through the example depending on the location. The new text created as a result of the 3rd phase is XoBatAK1919. Time-dependent re-encryption is done through this text. Application3 + Application $2=$ Application 4.

(a) Time information is taken.

(b) The number written with 6-digit $(1,2,3,4,5,6)$ elements is taken.

(c) The number taken is matched with groups and time information.

Let's match the 6 main elements of time with the 6 main structures that will create our text.

\begin{tabular}{|l|l|}
\hline \multicolumn{2}{|c|}{ 1st Group } \\
\hline 1 & UPP.VOWEL \\
\hline 2 & UPP.CONSONANT \\
\hline 3 & LOW.VOWEL \\
\hline 4 & LOW.CONSONANT \\
\hline 5 & NUMBER \\
\hline 6 & SYMBOL \\
\hline
\end{tabular}

\begin{tabular}{|l|l|}
\hline \multicolumn{2}{|c|}{ 2nd Group } \\
\hline 1 & DAY \\
\hline 2 & MONTH \\
\hline 3 & YEAR \\
\hline 4 & HOUR \\
\hline 5 & MINUTE \\
\hline 6 & SECOND \\
\hline
\end{tabular}

Example 2.5. Let's take the number 312546. Let's our time be 09.01.2020/19.44.01.

In this case:

$\begin{array}{lll}\text { Uppercase vowels } & \leftrightarrow & \text { Year } \\ \text { Uppercase consonants } & \leftrightarrow & \text { Day } \\ \text { Lowercase vowels } & \leftrightarrow & \text { Month } \\ \text { Lowercase consonants } & \leftrightarrow & \text { Minute } \\ \text { Number } & \leftrightarrow & \text { Hour } \\ \text { Symbol } & \leftrightarrow & \text { Secinds }\end{array}$

As a result of this match, transactions are done and the remainder is calculated one by one, each group is shifted as much as the remainder, our text then becomes encrypted.

$\begin{array}{lll}\text { Day } & \leftrightarrow & (\bmod 24) \\ \text { Month } & \leftrightarrow & (\bmod 8) \\ \text { Year } & \leftrightarrow & (\bmod 8) \\ \text { Time } & \leftrightarrow & (\bmod 10) \\ \text { Month } & \leftrightarrow & (\bmod 24) \\ \text { Seconds } & \leftrightarrow & (\bmod 10)\end{array}$

\begin{tabular}{|l|c|c|c|c|c|c|}
\hline & $\begin{array}{c}\text { Uppercase } \\
\text { Vowel }\end{array}$ & $\begin{array}{c}\text { Uppercase } \\
\text { Consonant }\end{array}$ & $\begin{array}{c}\text { Lowercase } \\
\text { Vowel }\end{array}$ & $\begin{array}{c}\text { Lowercase } \\
\text { Consonant }\end{array}$ & Number & Symbol \\
\hline MODE & 8 & 24 & 8 & 24 & 10 & 10 \\
\hline MATCH & 3 & 1 & 2 & 5 & 4 & 6 \\
\hline TIME & 2020 & 09 & 01 & 44 & 19 & 01 \\
\hline REMAINDER/SHIFT & 4 & 9 & 1 & 20 & 9 & 1 \\
\hline
\end{tabular}

\begin{tabular}{|c|c|c|c|c|}
\hline & $\rightarrow$ & $C$ & $\rightarrow$ & $A C E$ \\
\hline & $\rightarrow$ & $o$ & $\rightarrow$ & $D F E C$ \\
\hline & $\rightarrow$ & $K$ & $\rightarrow$ & $A A G D$ \\
\hline & $\rightarrow$ & $e$ & $\rightarrow$ & $D G B C$ \\
\hline & $\rightarrow$ & $q$ & $\rightarrow$ & $D F B$ \\
\hline & $\rightarrow$ & $A$ & $\rightarrow$ & $A C D$ \\
\hline & $\rightarrow$ & K & $\rightarrow$ & $A B C D$ \\
\hline & $\rightarrow$ & 0 & $\rightarrow$ & $D D$ \\
\hline & $\rightarrow$ & 8 & $\rightarrow$ & $B B$ \\
\hline & $\rightarrow$ & 0 & $\rightarrow$ & $D D$ \\
\hline & $\rightarrow$ & 8 & $\rightarrow$ & $B B$ \\
\hline & $\rightarrow$ & ? & $\rightarrow$ & $C D$ \\
\hline
\end{tabular}


Our last encryption becomes: CöKeqAK0808?

\section{Findings}

Our encryption method can be expressed in 4 different ways:

1. Our first model is based on mathematics and music, expressing ASCII numbers with the additive property of Fibonacci and Lucas numbers and converting them into notes.

2. In addition to our first model, a time variable encryption program is created.

3. In addition to our first model, a location variable encryption program is created.

4. In addition to our first model, a time and location variable encryption program is created.

An algorithm containing English characters is created with the software of the first encryption method.

\section{Conclusion and discussion}

As a result of the literature review, it was realized that there was no encryption method made using the properties of mathematical number strings and musical instruments. In the study, 6 main titles are determined for letters, numbers, and symbols. Then ASCII codes of letters, numbers, and symbols are assigned. Being expressed by Fibonacci and Lucas number sequences, these codes are encoded with 4 different variables: time, location, and time-location. The codes were matched with the notes to be played with the violin. It is found that the hypothesis that is the basis of the research is feasible.

- Most of the encryption methods are made with a certain logic over a single main text. Our main text components are divided into 6 main groups and encryption diversity is created and a program that is difficult to encrypt is done. It has been determined that other encryption programs do not have lowercase-uppercase, vowel-consonant, number-symbol distinctions. In encryption, various transition methods have been determined to avoid confusion between the 6 main groups.

- 4 different one on the basis, encryption moves from easy to difficult:

1. ASCII codes $\rightarrow$ Fibonacci and Lucas numbers $\rightarrow$ Note

2. ASCII codes $\rightarrow$ Fibonacci and Lucas numbers $\rightarrow$ Time variable $\rightarrow$ Note

3. ASCII codes $\rightarrow$ Fibonacci and Lucas numbers $\rightarrow$ Location variable $\rightarrow$ Note

4. ASCII codes $\rightarrow$ Fibonacci and Lucas numbers $\rightarrow$ Time and Location variable $\rightarrow$ Note

Encryption systems have been established. It is seen that it differs from other encryption programs as the richness of application.

- The encryption system we have created can be transmitted both in audio and text. At the same time, it offers diversity in terms of data privacy as it can be applied with various instruments (piano-violin-viola-cello, etc.).

- The encryption method in the research is suitable for people who have musical knowledge. People having a good musical ear can audibly encrypt the password regardless of any written source. Due to these features, it differs from the encryption methods made so far. In addition, the data transfer can be transferred as solo and choral.

- The encryption method created is a difficult method to be encrypted because it contains many details between Fibonacci and Lucas number sequences, ASCII codes, and notes.

- The most common encryption method is the solution of objects through the possibilities of using them in a text according to languages. In this research, it is seen that the same object $(2,3,4)$ applications create a richness of being transferred in different ways in different locations / times / locations and times.

- In other encryption methods, it has been determined that encrypting an object is one step. But in this study, the same text differs as time changes and location changes. This allows the same object to be encoded differently in a text.

- One of the disadvantages of our study is that communication between any two people who do not have sufficient musical knowledge is not healthy. Environmental conditions (noise, etc.) can affect the efficiency of the audio transmission.

- Since it is applied manually in terms of application, time and personal errors are possible, even if small. This disadvantage has been removed by transforming the method into a software program to create ease of application and speed.

- The encryption method being created is based on the Turkish alphabet.

- It can be done in accordance with other alphabets. The number of symbols used can be increased to increase the variety of applications.

- In the research, simple translation encryption is done based on the remaining. Application with the asymmetric encryption method can make it a very difficult system to be encrypted.

- Fibonacci and Lucas number sequences were used in the research. Different encryption methods can be developed by changing the number of strings used. If software that detects notes can be created, the program can also be used commercially (military-data security-banking, etc.). Encryption can be implemented in a music piece with the help of a melody, which is more difficult, complex, and secret to be decoded.

\section{References}

[1] Ç. Özyılmaz, Introduction to Cryptology, Master Thesis, Karabuk University, 2014.

[2] M. Aghayev, On Cryptology and Data Encryption Techniques, Master Thesis, Ege University, 2017.

[3] Z. H. Obaid, Comparison of Cryptology Methods, Master Thesis, Erciyes University, 2016.

[4] S. Bakım, Investigation of the Use of Fibonacci Sequence and Golden Ratio in Music, Master Thesis, Selçuk University, 2014.

[5] A. Esi, Mathematics and music, J. Awareness, 2(3S) (2017), 631-642.

[6] C. Orhan, Matematik ve müzik, Matematik Dünyası, 6(1995), 6-7.

[7] A. Dikici, Investigation of the Effect of Music Education Provided with Orff Technique on Mathematical Ability, Ph.D. Thesis, Ankara University, 2002.

[8] G. Kuzuoğlu, Divisibility Properties of Some Sequences Related to Fibonacci Numbers, Master Thesis, Kocaeli University, 2019. 
[9] C. Bolat, Properties and Applications of K-Fibonacci, K-Lucas Numbers, Master Thesis, Selcuk University, 2008.

[10] G.Karadeniz, Zeckendorf Representation of Fibonacci and Pell Numbers and Integers, Master Thesis, Gazi University, 2006

[11] S. Nasibov, On Cryptology Systems and Applications, Master Thesis, Ege University, 2015.

[12] D. Tymoczko, A Geometry of Music: Harmony and Counterpoint in the Extended Common Practice, Oxford University Press, New York, 2011.

[13] U. Bora, A key point where science and art cross: Mathematics and music relationship, J. Uludağ Univ. Fac. Educ., 15(1) (2002), 53-68.

[14] E. Riedel, The Relationship Between Music Instruction and Academic Achievement in Mathematics by Nechelle Nipper Sharpe, Walden University, USA, 2013

[15] G. Göğüş, The relation between musical and mathematical learning success, J. Uludağ Univ. Fac. Educ., 21(1) (2008), 79-89.

[16] I. Kaya, Contributions of Pythagoras and Archytas to the Mathematical Music Theory, Master Thesis, Mimar Sinan Fine Arts University, 2009.

[17] S. Beytekin, Mathematical Analysis of Jazz on Piano and Analysis of Its Relationship with Fractal Geometry, Master Thesis, 2015.

[18] U. Biçak, A New Harmony Theory With Solar Voyage For Orchestra In the Context of the Relationship Between Music and Mathematics, Master Thesis, Mimar Sinan Fine Arts University, 2018.

[19] İ. Kaya, The relation between monochord string splits and harmonics, Electron. J. Soc. Sci., 16(61) (2017), 636-646.

[20] G. E. Roberts, From Music to Mathematics: Exploring the Connections, Johns Hoplinks University Press, Baltimore, 2016.

[21] I. Lehmann, A. Posamentier, The Fabulous Fibonacci Numbers, Prometheus Books, New York, 2007.

[22] A. Gökhan, ASCII Codes of Lowercase \& Uppercase Letters, Accessed Date: 12.10.2019, available at http://www.phpservisi.com/ kucuk-buyuk-harflerin-ascii-kodlari/. 